\title{
Read all about it
}

\author{
Stephen Hancocks OBE \\ Editor-in-Chief
}

The BDJ Upfront section includes editorials, letters, news, book reviews and interviews. Please direct your correspondence to the News Editor,

Kate Quinlan at BDJNews@nature.com. Press releases or articles may be edited, and should include a colour photograph if possible.

$\mathrm{T}$ he notion that research is not relevant to our daily lives is nonsense. What most often happens is that we do not realise that we are constantly researching for ourselves, or perhaps more correctly, we do not think of what we are doing as research. How sophisticated is the most up-to-date handpiece? Where can I find a restaurant near to the cinema? The method may not be that of randomised, controlled trials, the results may not be worthwhile publishing and the conclusions may not be relevant to anyone but ourselves unless we are providing restorative dental treatment or eating with friends, in which case they very much are; but it is research nonetheless.

The point is that the sequence of research, under whatever name we give it, is central not only to our work and leisure pursuits but to survival itself. As with so much else, it is the context that changes and not the fundamental activity. For busy clinicians dental research can often seem like an esoteric luxury which feeds little or nothing into their everyday lives. A frequently expressed view is, where is the relevance to me? In fairness, it is sometimes a difficult question to answer; the reason for the work can sometimes seem to be more self-serving to the author than for any other wider humanitarian or philanthropic purpose. To some extent the value of the research is often dictated by the relevance of the hypothesis posed, as I indicated in a previous editorial.

However, in terms of context a further crucially important element is the way in which the research is communicated. Historically, this has been by what I like to call the 'worthy' method. This involves it being worthy, the publication of it in a scientific journal looking worthy and the reader being expected to spend a lot of time treating it as worthy. The net result is that we either do not bother at all, decry it as irrelevant or (very importantly) feel guilty about both of these reactions. We are professionals and so we feel we should be but we no longer have time to be, nor can afford to be worthy.

One solution to this conundrum is to be less deferential whilst simultaneously remaining as reverential. What we have been attempting to do at the $B D J$ is to continue to publish research but in such a way as to bring out its relevance efficiently, effectively and in a readable and interesting way. The seeds of this reality, based in forward-thinking publishing practice, were planted some ten last year from over 150 countries.

In deciding to develop this very favourable interaction we have redesigned the pages of the journal and further utilised technology, especially social media, to bring increased transparency and clarity to the research that we publish. The newly refreshed pages are designed to make navigation easier and more pleasing to the eye. The enhanced monthly feature Research Insights will bring valuable additional context to dental research with article summaries from across

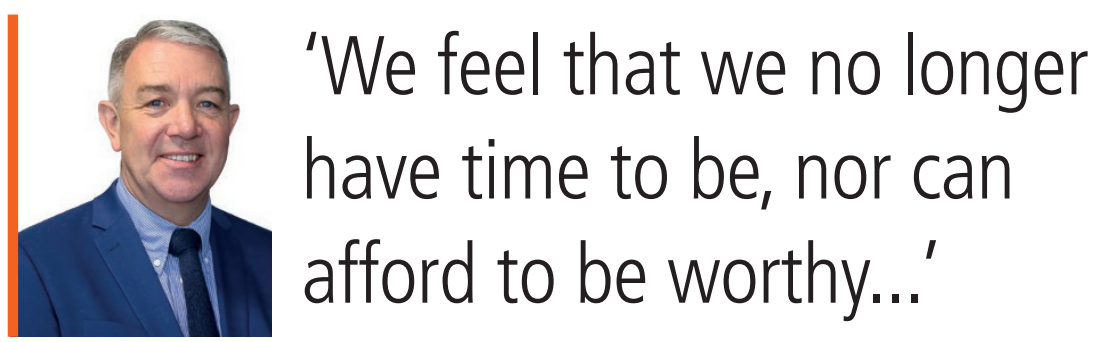

or so years ago when we switched from publishing research in full in the printed version of the journal to placing this online but adding a 'research summary' in the hard copy. Pandemonium broke out. It was inconvenient, it made no sense, questions were asked at the BDA's (then) Representative Body. I think it was about guilt. I think it was about feeling that someone had publically exposed our collective secret about not being able to be worthy.

Time healed this raw wound. Readers began to see the advantage of the research summaries which, basically, told stories. Why was the research initiated, what was discovered, why might the results be useful, what did an expert think, why did we publish it and what would the authors like to do as a follow on? Umm, when you put it like that it is actually quite interesting and I might go online to read more. Our data show that more and more and more readers have done just that not only in the UK but worldwide; in excess of four million visitors the BDJ Portfolio, expert commentary and increased accessibility with infographic visuals and video abstracts. Meanwhile BDJ Bites (go. nature.com/bdjyoutube) presents short audio summaries highlighting recent research as an adjunct for the time-strapped listener. Also, crucially importantly, these developments are providing access for dental researchers to new, increased and more engaged audiences, making us the place to be published in order to get important work more widely read and recognised. The advent of altmetrics as a modern measure of reader and broadcaster engagement reinforces this by placing the $B D J$ as the number one dental journal in the world, ${ }^{2}$ a position that confirms our consistently high ranking in immediacy index. And how has all this been possible? Research.

DOI: $10.1038 /$ sj.bdj.2016.540

1. Hancocks S. Asking the right questions. Br Dent J 2016; 221: 47.

2. Kolahi J, Khazaei S. Altmetric: Top 50 dental articles in 2014. Br Dent J 2016; 220: 569-574. 